\title{
SCIAMACHY stratospheric aerosol extinction profile retrieval using the OMPS/LP algorithm
}

\author{
G. Taha ${ }^{1}$, D. F. Rault ${ }^{2}$, R. P. Loughman ${ }^{3}$, A. E. Bourassa ${ }^{4}$, and C. von Savigny ${ }^{5}$ \\ ${ }^{1}$ Science Systems and Applications Inc. Lanham, MD, USA \\ ${ }^{2}$ NASA Langley Research Center, Hampton, VA, USA \\ ${ }^{3}$ Center for Atmospheric Sciences, Hampton University, Hampton, VA, USA \\ ${ }^{4}$ Department of Physics and Engineering Physics, University of Saskatchewan, Saskatoon, Canada \\ ${ }^{5}$ Institute of Environmental Physics, University of Bremen, Bremen, Germany
}

Received: 28 October 2010 - Published in Atmos. Meas. Tech. Discuss.: 24 November 2010

Revised: 2 March 2011 - Accepted: 11 March 2011 - Published: 16 March 2011

\begin{abstract}
The Ozone Mapper and Profiler Suite, Limp Profiler (OMPS/LP) algorithm is used to retrieve ozone concentration and aerosol extinction profiles using a series of 120 SCIAMACHY limb measurements collocated with SAGE II solar occultation events. The primary goal of the study is to ascertain the capability of the OMPS/LP retrieval algorithm to accurately retrieve the vertical distribution of stratospheric aerosol extinction coefficient so as to better account for aerosol effects in the ozone profiling retrieval process. Using simulated radiances, we show that the aerosol extinction coefficient can be retrieved from limb scatter measurements within $5 \%$ and a standard deviation better than $15 \%$, which is more than sufficient to improve the OMPS/LP ozone products to be used as Environmental Data Records. We also illustrate the ability of SCIAMACHY limb measurements to retrieve stratospheric aerosol extinction profiles with accuracy comparable to other instruments. The retrieved aerosol extinction profiles agree with collocated SAGE II measurements on average to within $25 \%$, with a standard deviation of $35 \%$.
\end{abstract}

\section{Introduction}

The Ozone Mapper and Profiler Suite (OMPS) mission will be launched on board the National Polar Orbiting Environment Satellite System (NPOESS) Preparatory Project (NPP) satellite in October 2011. The main goal of the mission is

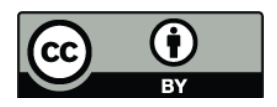

Correspondence to: G. Taha

(ghassan.taha-1@nasa.gov) to produce Environmental Data Records (EDR) for total column ozone and ozone concentration vertical distribution over the whole Earth atmosphere. The present paper is concerned with one of the OMPS suite of instruments, namely the Limb Profiler (LP), which will use the measurements of scattered solar radiation to infer information on the ozone concentration vertical profile. More specifically, the paper is primarily focused on aerosol extinction profile retrieval and its effect on the quality of the retrieved ozone concentration profile. In order to test the OMPS retrieval algorithm, we use a simulated set of radiances and the limb scattering measurements of SCIAMACHY on board of Envisat. Another objective of this paper is to illustrate the capabilities of SCIAMACHY limb measurements to derive stratospheric aerosol extinction profiles, since this work presents the first results of such a retrieval.

Stratospheric aerosols are an important parameter in the modeling of climate change and also play an important role in the chemical and dynamic processes related to ozone destruction in the stratosphere. Stratospheric aerosol has been measured with ground-based lidar (Poole and McCormick, 1988), balloon-borne Optical Particle Counters (OPC) (Hofmann and Deshler, 1991), and satellites such as the Stratospheric Aerosol Measurement (SAM II) (McCormick et al., 1982), the Stratospheric Aerosol and Gas Experiment (SAGE II) (Thomason, 1991), and SAGE III (Thomason and Taha, 2003). The capability to retrieve atmospheric aerosol extinction properties globally from limb scatter (LS) measurements is particularly important at the present time, as no solar occultation sensors, which have been relied upon in the past 30 years, are currently active. At present, two LS sensors, namely the Optical Spectrograph and Infrared Imager

Published by Copernicus Publications on behalf of the European Geosciences Union. 
System (OSIRIS) (Llewellyn et al., 2004), and the SCanning Imaging Absorption spectroMeter for Atmospheric ChartograpHY (SCIAMACHY) (Bovensmann et al., 1999) are still in operation, while the OMPS is expected to launch this year. The capability of LS sensors has already been demonstrated with SAGE III LS (Rault and Loughman, 2007) and OSIRIS (Bourassa et al., 2007) measurements. Aerosol extinction profiles are also measured by the stellar occultation Instrument Global Ozone Monitoring by Occultation of Stars (GOMOS) (Vanhellemont, et al., 2010).

The paper reviews the main concepts of the OMPS/LP retrieval algorithm in Sect. 2. The performance of the OMPS/LP algorithm is illustrated in Sect. 3 where a set of synthetic LS radiance data are used to test the algorithm. It is shown that the OMPS/LP algorithm can accurately retrieve all the input parameters, namely surface reflectance, aerosol extinction, ozone density as well as tangent height registration (TH). The OMPS/LP algorithm is applied to SCIAMACHY data as shown in Sect. 4. A series of 120 SCIAMACHY LS events are selected which correspond to close coincidences with SAGE II solar occultation events in both space (less than $250 \mathrm{~km}$ ) and time (less than one day) during 2004. The retrieved aerosol extinction profiles are presented, discussed and compared with SAGE II, first on a case by case basis and then on a global statistical level. The ozone concentration retrieval results are presented and compared with both SAGE II and SCIAMACHY archived products. Finally, a summary and conclusions of this study are presented in Sect. 5 .

\section{Methodology}

\subsection{OMPS/LP retrieval algorithm}

The retrieval of atmospheric constituents from limb radiance measurements involves comparing measured data with simulated data generated by a multiple scattering radiative transfer (RT) model. The RT model used for the LP was initially developed by Herman et al., (1994, 1995), and has been tuned and optimized for limb studies by Rault (2005). It is efficient in performing multi-wavelength computations, which allows one to perform convolution with the instrument slit function with sufficient accuracy and speed. The partial derivatives are computed semi-analytically for both ozone (single scattering) and aerosol (multiple scattering). The retrieval algorithm is based on the Rodgers nonlinear optimal estimation technique (Rodgers, 2000).

For the ozone concentration retrieval, the measurement vector is made of wavelength pairs and triplets, following the technique described by Flittner et al. (2000). The a priori data vector is provided for a given latitude and calendar month from the SAGE II climatology. For the aerosol extinction retrieval, the measurement vectors are normalized radiances at specific wavelengths corresponding to weak gaseous absorp- tion. The a priori vector is a set of extinction vertical profiles (8 wavelengths) corresponding to the present period of low stratospheric background aerosol extinction constructed from SAGE III measurements, and is fixed for all locations. The a priori aerosol size distribution is assumed to be a background stratosphere aerosol of a single mode log normal distribution, with $0.06 \mu \mathrm{m}$ mode radius and variance $\sigma$ of 1.73 , composed of spherical liquid sulphate particles with an index of refraction $m=1.448+0 i$ (Yue and Deepak, 1983; Wang et al., 1996). In the forward model, the atmospheric temperature and pressure profiles are generated from the $\mathrm{Na}-$ tional Centers for Environmental Prediction (NCEP) dataset (Kalnay et al., 1996), and the $\mathrm{NO}_{2}$ information is taken from a climatology constructed using the PRATMO photochemical box model (McLinden et al., 2000). The retrieval uncertainties or Residual Standard Deviation (RSD) are evaluated from the diagonal of the covariance matrix, which itself is computed using the Signal-to-Noise-Ratio (SNR) specific to the sensor.

The OMPS/LP profile retrieval algorithm is composed of a series of sequential steps; first cloud height is determined using long wavelength channels with weak gaseous absorption, secondly, a tangent height registration check is performed, and adjusted, if necessary (not adjusted in this study), using a scene-base method, such as the Rayleigh Scatter Altimeter Sensor (RSAS) technique (Janz et al., 1996). The third step consists of estimating the effective scene reflectivity (or albedo) by comparing the measured and modeled radiances in the TH range of $35-45 \mathrm{~km}$. Fourth, the aerosol extinction and size distribution are then retrieved, as described below, using spectral channels with weak gaseous absorption. TH registration is repeated using the retrieved aerosol extinction profiles, since the TH registration is somewhat sensitive to aerosol loading. Finally, the ozone concentration retrieval is performed using radiance data from both the ultraviolet and visible wavelength channels respectively, for high altitudes $(30-60 \mathrm{~km})$ and low altitudes (Cloud top or 10-40 km).

\subsection{Aerosol extinction algorithm}

The retrieval algorithm solves for the aerosol extinction at several wavelengths $(524,692,750,793$, and $1028 \mathrm{~nm})$ across the measured spectrum, and then uses that spectral information to infer information on the size distribution. Radiances are normalized to their value at $35.5 \mathrm{~km}$, where aerosol extinction contribution is negligible. Rodgers' maximum likelihood technique is used to retrieve the extinction coefficients independently for each wavelength and the process is allowed to iterate up to convergence, similar to Rault and Loughman (2007). A median Angström coefficient is determined from the retrieved extinctions at the different wavelengths, and used to calculate the extinction coefficients at the wavelengths used by the ozone concentration retrieval, thus ensuring that the aerosol extinction coefficients are smooth functions of wavelength and therefore do 


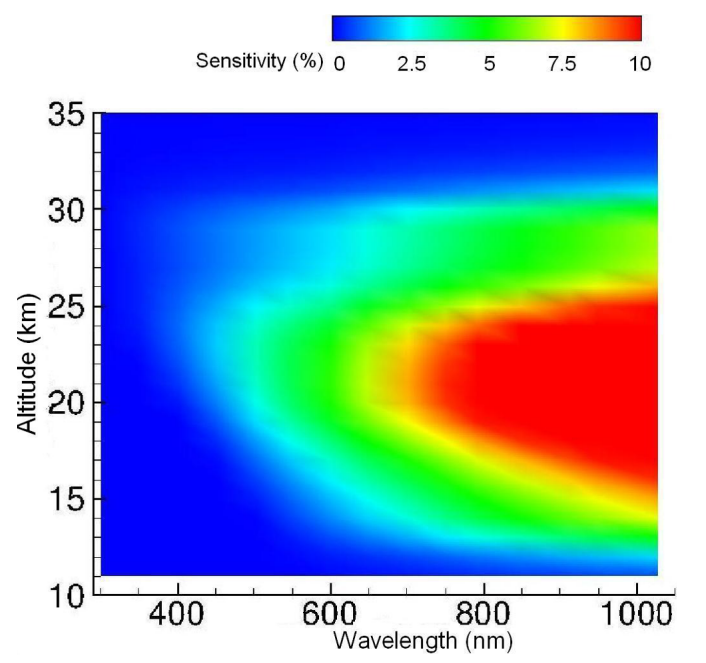

Fig. 1. Sensitivity of SCIAMACHY limb radiance to stratospheric aerosol. Sensitivity is defined as the maximum change [\%] of limb radiance due to $1 \%$ change in aerosol extinction.

not introduce non-physical high frequency fluctuations into the ozone concentration retrieval process. The aerosol extinction profile is also updated at the RSAS channel, usually at $\sim 350 \mathrm{~nm}$, where the Rayleigh scattering is dominant and gaseous absorption is minimal, to improve the accuracy of the tangent height predictions. An alternative method to the Angström approach consists in using the retrieved multiple wavelength aerosol extinction to solve for a moment of the size distribution (Rault and Loughman, 2007). In this work, we are only presenting results obtained using the first approach.

Figure 1 is a plot of the sensitivity of SCIAMACHY LS signal to aerosol $\left[d \log \left(\mathrm{I}_{\lambda}\right) / d \log \left(\beta_{\lambda}\right)\right]$, which shows clear aerosol extinction sensitivity at wavelengths in the 500-1020 range. The optimal vertical altitude of the aerosol signal varies by wavelength, generally from $18-25 \mathrm{~km}$ at $520 \mathrm{~nm}$ to $12-30 \mathrm{~km}$ at $1020 \mathrm{~nm}$. At shorter wavelengths, Rayleigh scattering dominates the scattering signal. Aerosol sensitivity is used to determine upper and lower limits of the retrieved aerosol extinction profile. The retrieval is not updated outside these limits.

\section{Results of synthetic data retrieval}

The retrieval algorithm was first tested with a relatively large synthetic dataset, where we have full control on the problem parameters. This step allows one to quantify retrieval uncertainties and perform a statistical analysis of the retrieved products.

This dataset was generated by a forward model and is composed of 450 limb scattering events. Each event corresponds to a co-location of a SAGE II occultation measurement with a SCIAMACHY limb scattering measurement. Co-locations
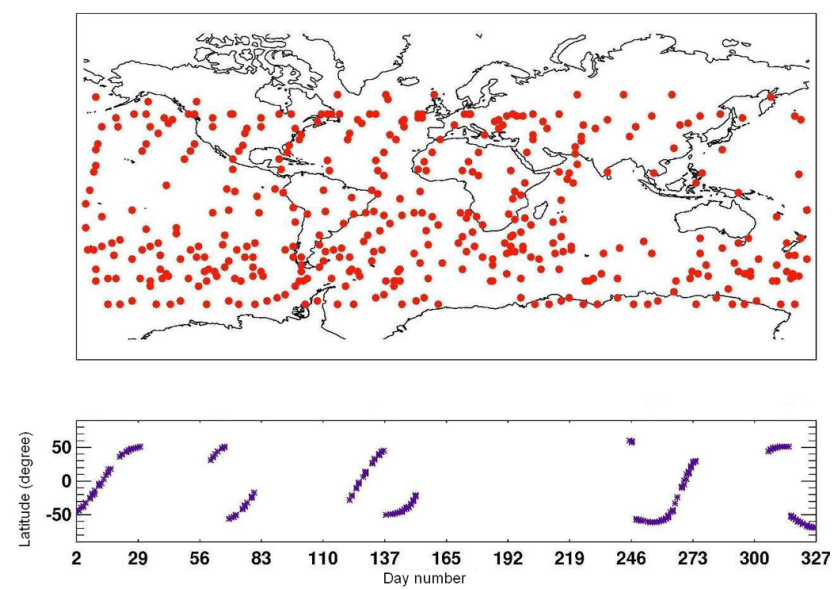

Fig. 2. Location of the simulated dataset (upper panel) and latitude (degree) vs. time (lower panel).

were searched for within a one year period. These events encompass a wide range of geo-locations, seasons, and solar viewing angles. The input ozone concentration, $\mathrm{NO}_{2}$, and aerosol extinction profiles for each event are those of SAGE II. The solar view angles are obtained from the SCIAMACHY measurements. The surface albedo is assumed to have a constant value of 0.15 , which represents clear sky conditions. The atmospheric temperature and pressure profiles are generated from NCEP reanalysis provided by the SAGE II data file. No noise or instrument errors are added to the radiances in this data set. The forward model is basically the same as the one used in the inversion retrieval; however, for the forward model run, we use a higher wavelength resolution, as well as finer single and multiple scattering grids than those used in the inversion mode. Figure 2 shows the simulated events location map. The lower panel is a plot of all events latitude vs. time.

The performance of the aerosol extinction retrieval is illustrated in Fig. 3, which compares the retrieved aerosol extinction profile to the assumed input profile or "truth". The figure shows the mean relative difference in percent (retrieval-truth) and the standard deviation of the retrievals for the 525 and $994 \mathrm{~nm}$ wavelengths. For the longer wavelength at $994 \mathrm{~nm}$, it can be seen that the aerosol extinction can be retrieved within $\sim 5 \%$ over the altitude range of $15-30 \mathrm{~km}$ and a standard deviation of $10-15 \%$. Similar differences and standard deviations can be seen for the shorter wavelength, $525 \mathrm{~nm}$, but for a reduced altitude range of $17-25 \mathrm{~km}$, and $25 \%$ outside that altitude range. The reduced altitude range for the $525 \mathrm{~nm}$ is correlated with reduced sensitivity to aerosol extinction at large Single Scattering Angle (SSA). Figure 4 is an example of aerosol weighting function or Jacobian matrix, at $525 \mathrm{~nm}$. The left panel is for a SSA of $132^{\circ}$ while the right panel is for a SSA of $34^{\circ}$. For the large SSA, the weighting functions are positive and strongly peaked at an altitude range of 20 $26 \mathrm{~km}$. At lower altitudes, aerosols scatter more light out of 


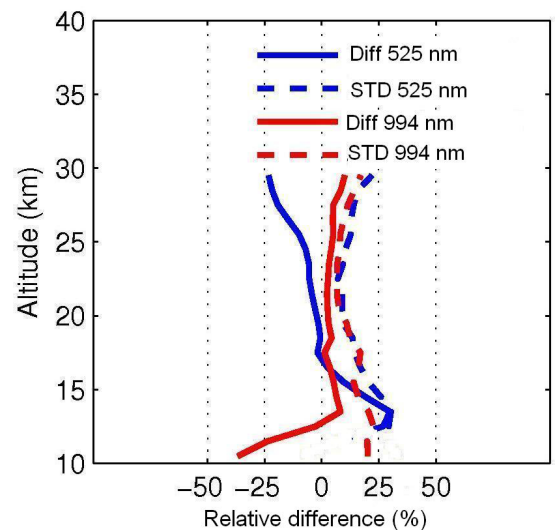

Fig. 3. Summary plot of the relative difference (percent) for all retrieved aerosol extinction profiles for the 450 simulated radiances. Blue $994 \mathrm{~nm}$, red $525 \mathrm{~nm}$. The dashed lines represent the standard deviations.
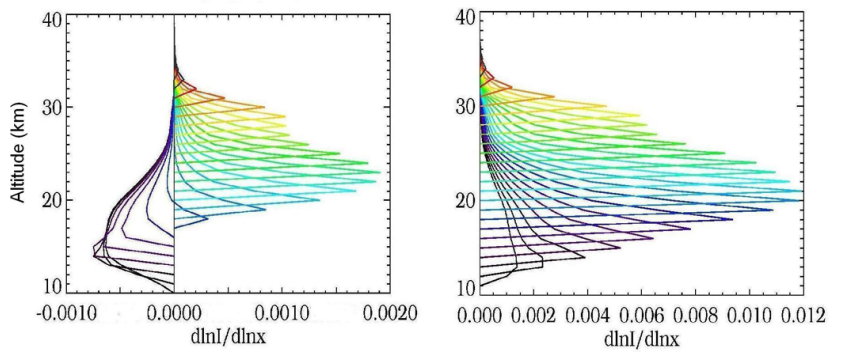

Fig. 4. Example of aerosol weighting functions at wavelength $525 \mathrm{~nm}$. The left panel is for the SSA $=133^{\circ}$, right panel is for $\mathrm{SSA}=43^{\circ}$, colored from black to red in altitude ascending order.

the line of sight beam than they do into it, which causes the weighting functions to go negative, and reduces the sensitivity of the limb radiance to aerosols. When the SSA is small, the weighting functions are always positive. Aerosol weighting functions are generally positive for large wavelengths, as demonstrated in Fig. 5 for the $994 \mathrm{~nm}$. To ensure maximum sensitivity towards aerosol, we use an initial guess profile of very low aerosol loading (Bourassa et al., 2009).

Results of the ozone concentration retrieval exhibit a relative difference of $2 \%$, and standard deviation less than $3 \%$, with respect to the true values at altitude range $20-58 \mathrm{~km}$, as depicted in Fig. 6. Aerosol modeling error in the forward model contributed up to $2 \%$ of the retrieval precision at altitude range $23-30 \mathrm{~km}$. In a separate test (not shown here) where the truth aerosol extinction profile spectral behavior is constrained by an aerosol size model, this bias disappears. Below $20 \mathrm{~km}$, the large standard deviation $\sim 15 \%$ is mainly caused by very low ozone concentrations at certain geographical regions. Although the absolute difference is generally small for all altitudes, the percent difference is further enhanced when the ozone concentration is very low.
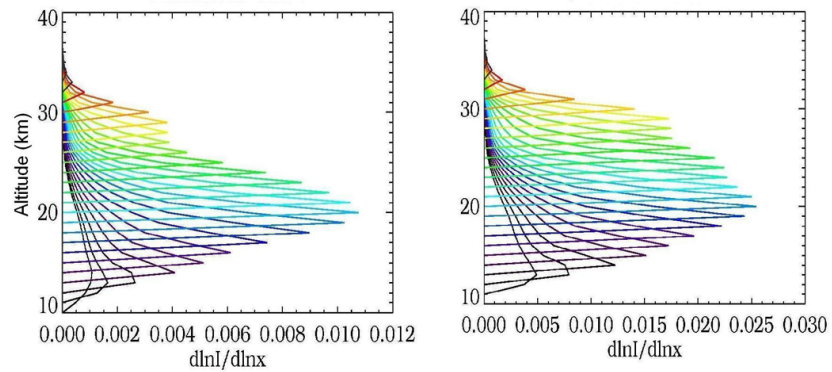

Fig. 5. Same as Fig. 4 now for wavelength $994 \mathrm{~nm}$.
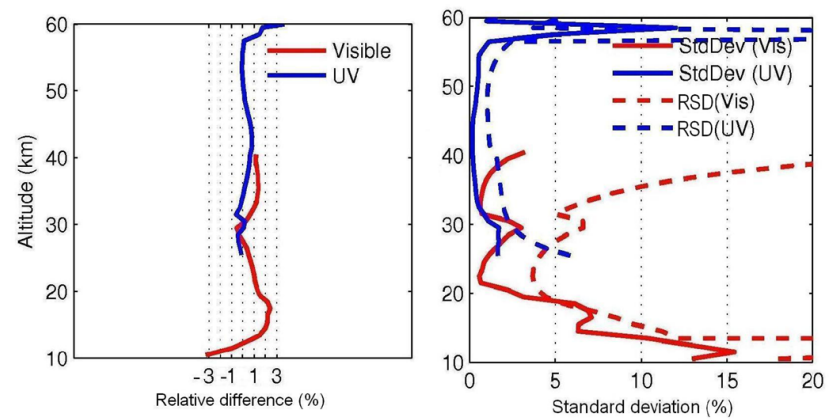

Fig. 6. Summary plot of the relative difference (percent) for all retrieved ozone profiles for the 450 simulated radiances, red is visible, and blue is UV retrievals (left panel). The right panel shows the standard deviation with the same color code. Dashed lines represent the retrieval error or RSD.

The accuracy of the retrieved ozone concentration clearly demonstrates that the retrieved aerosol extinction is sufficiently ascertained and can accurately correct for the aerosol effect on the ozone concentration retrieval. Rault and Taha (2007) showed that ignoring the aerosol contribution would produce an ozone density bias of up to $7 \%$ in the region of maximum aerosol extinction, while the use of constant aerosol extinction climatology instead of retrieving it can introduce a systematic bias and a possible seasonal or geographical signature in the ozone concentration retrieval around the aerosol extinction layer.

The effective albedo retrieval is within $11 \%$, with a standard deviation of $25 \%$. The retrieved tangent height accuracy is within $75 \mathrm{~m}$ and a standard deviation of $80 \mathrm{~m}$. The retrieved tangent height is $-265 \mathrm{~m}$ and a standard deviation of $240 \mathrm{~m}$ if an aerosol extinction climatology is used instead of the retrieved profile. 


\section{Results of SCIAMACHY retrievals}

\subsection{SCIAMACHY dataset}

The SCIAMACHY instrument on board Envisat (Environmental Satellite) has been in orbit since 2002, performing limb scatter radiance measurements from the near UV to the infrared region (For instrumental details we refer to Bovensmann et al., 1999). SCIAMACHY limb products include vertical profiles of ozone, $\mathrm{NO}_{2}, \mathrm{BrO}, \mathrm{H}_{2} \mathrm{O}$, and $\mathrm{OClO}$, as well as polar stratospheric and noctilucent clouds. A fairly good estimate of the aerosol extinction profile is critical to the retrieval accuracy of stratospheric minor constituent profiles, mainly in the Upper Troposphere-Lower Stratosphere (UT/LS) region, as shown by Loughman et al. (2005) and Rault and Taha (2007). For this study SCIAMACHY Level 1 version 6.03 data are used, that includes an improved tangent height registration compared to the lower Level 1 versions used by von Savigny et al. (2005). The accuracy of the tangent height registration is assumed to be better than $300-400 \mathrm{~m}$.

In this paper, a subset of 120 SCIAMACHY events recorded in 2004 was selected. Each event corresponds to a geo-location in close proximity to a SAGE II solar occultation, within $250 \mathrm{~km}$ and within $24 \mathrm{~h}$. SAGE II is widely recognized as a benchmark for satellite ozone and aerosol extinction measurements in the stratosphere (Wang, et al., 2002; Borchi, et al., 2004; Thomason and Peter, 2006). An OMPS proxy dataset was constructed from SCIAMACHY data by selecting radiance measurements at OMPS wavelengths, and convolving each radiance with the OMPS spectral instrument point spread function. The radiance data was then interpolated to a $1 \mathrm{~km}$ grid. A spatial Gaussian convolution with a Full Width Half Maximum (FWHM) of $2.7 \mathrm{~km}$ was also applied to the forward model to match the SCIAMACHY Field of View (FOV) function. As shown in Fig. 7, the proxy dataset is evenly distributed around $50^{\circ} \mathrm{N}$ and $70^{\circ} \mathrm{S}$, and with time, allowing us to study the effect of seasonal/geographical variations on the ozone concentration and aerosol extinction retrieval. When comparing retrieval products, SAGE II aerosol extinction and ozone concentration profiles are convolved with a $2.5 \mathrm{~km}$ Gaussian filter to match the SCIAMACHY FOV function.

Figure 8 is a plot of the difference between SCIAMACHY normalized measured $\left(y_{\text {meas }}\right)$ and modeled radiance $\left(y_{\text {clean }}\right)$ for an aerosol free atmosphere, at 524, 692, 750, 793, and $1028 \mathrm{~nm}$. Initial normalization altitude is $35.5 \mathrm{~km}$. The signature of stratospheric aerosols is clearly evident from 12 to $30 \mathrm{~km}$, with aerosol sensitivity increasing with wavelength. SCIAMACHY LS measurements show evidence of straylight at high altitudes, with the strongest contamination occurring at longer wavelengths (Gottwald et al., 2006). The straylight can be observed above $32 \mathrm{~km}$ for all wavelengths except for the $1028 \mathrm{~nm}$, where it was above $29 \mathrm{~km}$. At high altitudes, the difference between the measurements and the clean atmosphere should be negligible. To avoid straylight
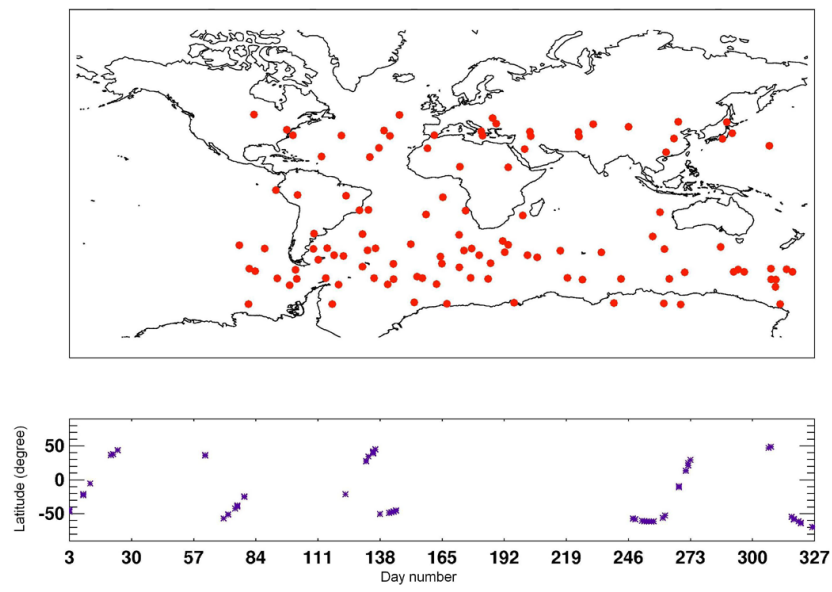

Fig. 7. Location of the SCIAMACHY measurement subset, (upper panel) and latitude (degree) vs. time (day number) (lower panel).

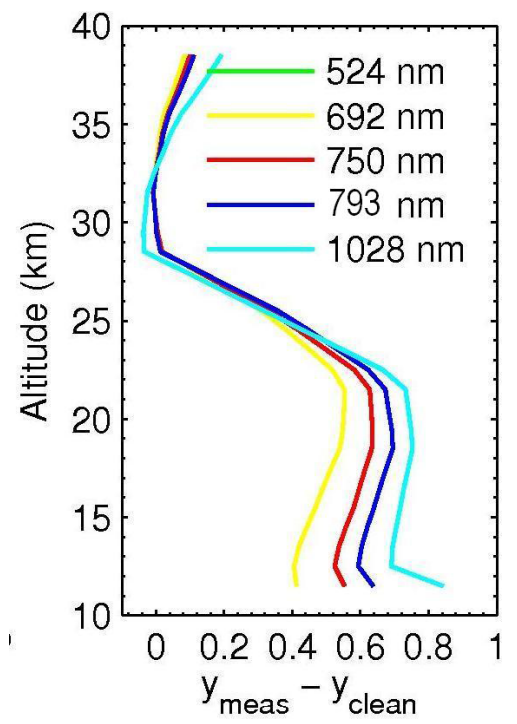

Fig. 8. Plot of the difference between SCIAMACHY normalized measured $\left(y_{\text {meas }}\right)$ and modeled radiance $\left(y_{\text {clean }}\right)$ with no aerosol, at $524,692,750,793$, and $1028 \mathrm{~nm}$.

contamination effects, the high-altitude normalization is adjusted to the height level where this difference is at its minimum. Normalization altitudes are constantly calculated and updated for each wavelength. The high-altitude normalization is needed to reduce the effects of parameters such as surface/cloud reflectance, sensor absolute calibration and sensor residual polarization.

\subsection{Aerosol extinction retrieval results}

Figure 9 shows the retrieved aerosol extinction profiles at $793 \mathrm{~nm}$ (left) and $1028 \mathrm{~nm}$ (right) and the a priori profile for the same event shown in Fig. 8. Usually it takes 24 iterations for the aerosol extinction retrieval to converge. 

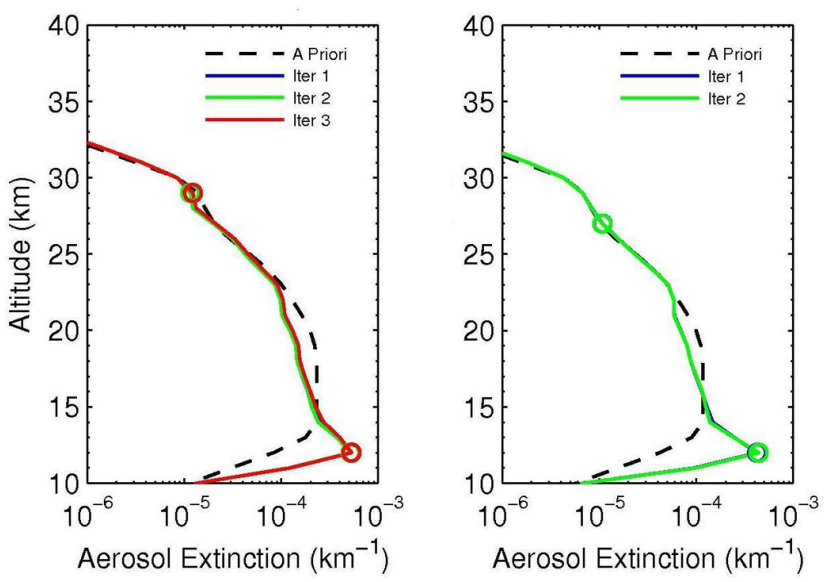

Fig. 9. Multiple iterations of retrieved aerosol extinction profiles at 793 (left) and $1028 \mathrm{~nm}$ (right) and the a priori profile.

The circles are positioned at the upper and lower limits of the retrieval for each iteration. The averaging kernel matrix for each selected wavelength is close to the identity matrix, which ensures that the retrieved aerosol extinction profile is mostly independent of the a priori profile within the retrieval limits, as can be seen in Fig. 9.

Two separate retrievals of aerosol extinction profiles from SCIAMACHY were performed using the following wavelengths: 750, 793, and $1028 \mathrm{~nm}$, and 524, 692, 750, 793, and $1028 \mathrm{~nm}$. For the second set of retrievals, the algorithm was modified to carry out an initial ozone concentration retrieval using aerosol extinction climatology. The aerosol extinction retrieval is then performed using the initial ozone estimate, in order to accurately account for the ozone interference at the shorter wavelengths. Finally, the ozone retrieval is performed using the retrieved aerosol extinction profiles This change, alongside the use of a very small aerosol extinction initial guess, was critical to successful retrievals of the shorter wavelengths, mainly 524 and $692 \mathrm{~nm}$. Unless stated otherwise, all presented results herein are using the first set of retrievals.

\subsection{Aerosol extinction retrieval comparison with SAGE II}

Figure 10 is an example of retrieved and calculated aerosol extinction profiles for the same event depicted in Figs. 8 and 9. It reveals a typical stratospheric aerosol extinction loading close to background levels on 24 January 2004, latitude $43.6^{\circ} \mathrm{N}$, and longitude $74.5^{\circ} \mathrm{E}$. The left panel shows the retrieved aerosol extinction profiles for 750, 793, and $1028 \mathrm{~nm}$ (color asterisk). The solid lines correspond to the 513$682 \mathrm{~nm}$ calculated using the Angström coefficient. The black lines refer to SAGE II measurements at 525 and $1020 \mathrm{~nm}$, whereas the dashed line refers to the interpolated SAGE II aerosol extinction at $750 \mathrm{~nm}$. The right panel is the rela-
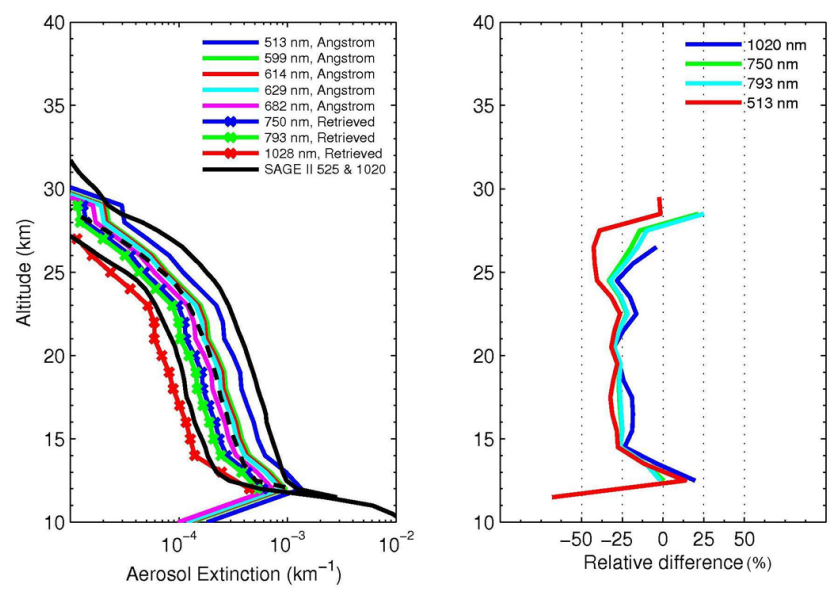

Fig. 10. The left panel shows the retrieved aerosol extinction profiles for 750, 793, and $1028 \mathrm{~nm}$ (color asterisk). Colored lines: 513$682 \mathrm{~nm}$ calculated aerosol extinction. Black lines: SAGE II profile at 525 and $1020 \mathrm{~nm}$. Dashed black line: interpolated SAGE II aerosol extinction profile at $750 \mathrm{~nm}$. The right panel shows the relative difference (percent) between the retrieved aerosol extinction profiles and the ones from SAGE II.
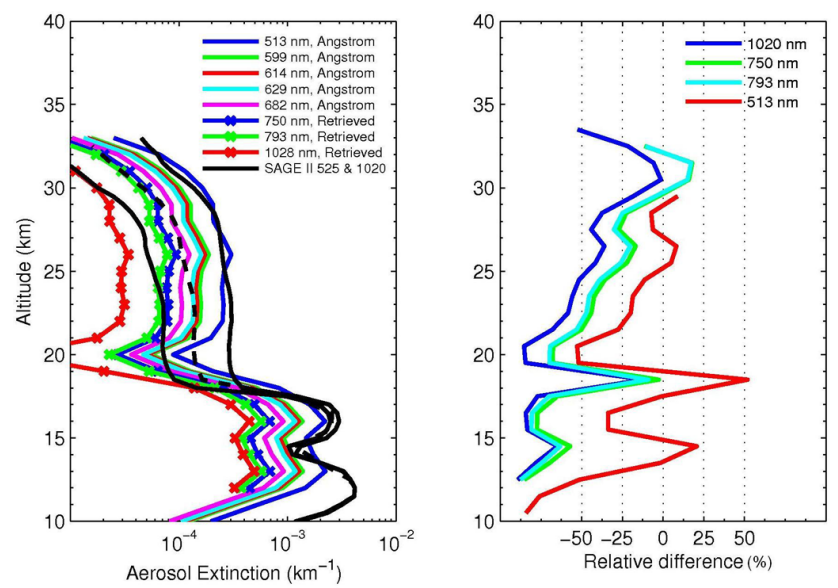

Fig. 11. Same as Fig. 10 but for 27 September 2004 , latitude $13.2^{\circ} \mathrm{N}$ and longitude $32.6^{\circ} \mathrm{E}$.

tive difference (percent) between the retrieved aerosol extinction and SAGE II profiles. For the purpose of comparison, SAGE II was linearly interpolated at wavelengths 513, 750 , and $793 \mathrm{~nm}$. Differences are shown at $513 \mathrm{~nm}$ (which is calculated), in order to illustrate the quality of the calculated aerosol extinction at the wavelength used in the ozone concentration retrieval.

The retrieved SCIAMACHY aerosol extinction profiles showed a good agreement with SAGE II with a flat difference of $25 \%$ at the altitude range of $12-28 \mathrm{~km}$. The shape of the retrieved aerosol extinction was in complete agreement with SAGE II. Both SCIAMACHY and SAGE II measurements at $12 \mathrm{~km}$ point to a cloud presence. 

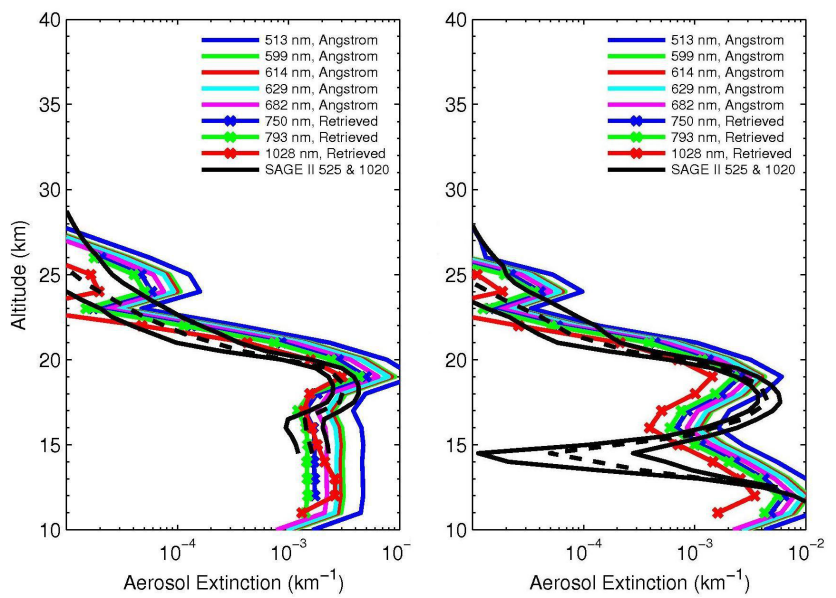

Fig. 12. Plot of the retrieved SCIAMACHY vs. SAGE II aerosol profiles, similar to Fig. 10 left panel, but for 13 September 2004, latitude $60.9^{\circ} \mathrm{S}$ and longitude $81.2^{\circ} \mathrm{W}$, and 9 September 2004, latitude $61.2^{\circ} \mathrm{S}$ and longitude $23.9^{\circ} \mathrm{W}$ respectively.

Figure 11 is similar to Fig. 10 but for 27 September 2004, latitude $13.2^{\circ} \mathrm{N}$ and longitude $32.6^{\circ} \mathrm{E}$. The aerosol extinction profile has a fairly unusual shape with multiple layers of aerosol extinction particles at 12,17 , and $20-30 \mathrm{~km}$. The origin of these multiple layers is not known, but it can be seen that SAGE II and SCIAMACHY are in reasonable agreement in detecting the aerosol extinction profile shape, but not necessarily the absolute magnitude. Reasons for this may be the basic assumptions made in the forward model regarding the aerosol size distribution uni-modal structure, shape, and composition (spherical sulphate particles) for the aerosol model in the retrieval algorithm. A different aerosol model is required to account for the tropospheric aerosol extinction seen at lower altitudes.

Figure 12 is another plot showing the retrieved SCIAMACHY and SAGE II aerosol extinction profiles, similar to Fig. 10 left panel, now for 13 September 2004, latitude $60.9^{\circ} \mathrm{S}$ and longitude $81.2^{\circ} \mathrm{W}$, and 9 September 2004, latitude $61.2^{\circ} \mathrm{S}$ and longitude $23.9^{\circ} \mathrm{W}$ respectively. This example demonstrates the ability of the retrieval to detect multiple layers of enhanced aerosol extinction, including thin Polar Stratospheric Clouds (PSCs). The NCEP temperature was 192-194 K around the observed aerosol extinction layers at $18-20 \mathrm{~km}$. The time, location, temperature, and magnitude of the extinction coefficient indicate that this layer is most likely a PSC. For the second case on the right panel, the retrieval manages to see through the cloud to detect a secondary aerosol extinction layer at $24-16 \mathrm{~km}$ that matches the SAGE II aerosol extinction profile shapes. The origin of this aerosol layer is the sedimentation of PSC particles carrying with them the background aerosol (Thomason and Peter, 2006). Although the agreement in profile shape between SCIAMACHY and SAGE II is notable, the absolute agreement is not so.

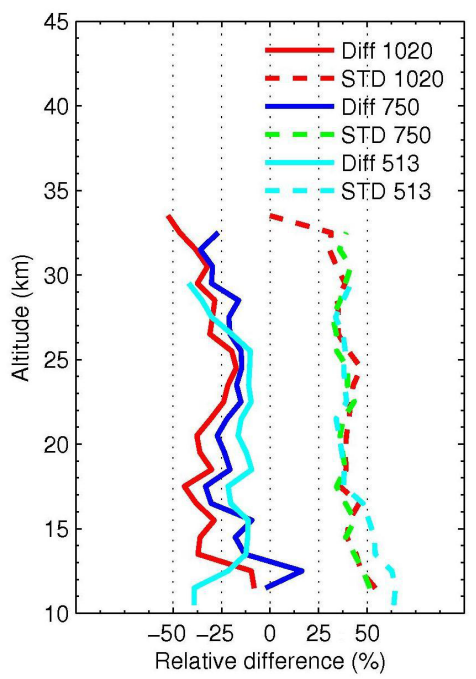

Fig. 13. Summary plot of the relative difference (percent) for all retrieved aerosol extinction profiles used in this study with SAGE II, which includes $1028 \mathrm{~nm}$ (red), $750 \mathrm{~nm}$ (blue) and $513 \mathrm{~nm}$ (cyan). The dashed lines are the standard deviations.

\subsection{Aerosol extinction retrieval overall statistics}

Figure 13 is a summary plot of the relative difference (percent) for all retrieved aerosol extinction profiles used in this study with SAGE II, which includes $1028 \mathrm{~nm}$ (red), $750 \mathrm{~nm}$ (blue), as well as the calculated $513 \mathrm{~nm}$ (cyan). The dashed lines are the standard deviations. In general, the SCIAMACHY retrieved aerosol extinction shows a good agreement with SAGE II, within $25 \%$. The $1028 \mathrm{~nm}$ channel shows a larger difference of $\sim 30-35 \%$, possibly because of spatial straylight contamination. The standard deviation is flat and within 30-35\%, which reflects on the larger variability of the observed differences. It also includes the real atmospheric variability between geo-locations of the SAGE II and SCIAMACHY observations. There were several events similar to the ones shown in Figs. 11 and 12, where the SCIAMACHY retrieval exhibit the correct aerosol shape, but not the absolute value, which can add to the large bias seen here. The SCIAMACHY aerosol extinction at $513 \mathrm{~nm}$, which is calculated using the Angström coefficient of the retrieved profiles, is within 10-15\% of SAGE II measurements, which reflects the quality of the aerosol extinction used in ozone concentration retrieval. The second set of aerosol extinction retrievals, which included 5 wavelengths, yielded similar results to the first set, but with an increased difference of 3-4 percent, and the retrieved $525 \mathrm{~nm}$ aerosol extinction, in general, demonstrated similar behavior as the longer wavelengths, but for a more restricted altitude range. For both sets of retrievals, the effect of aerosol extinction on the retrieved ozone concentration was similar, which indicates that the Angström model used to predict the aerosol extinction at shorter wavelengths is reasonably accurate for this purpose. 
Sources of the observed difference with SAGE II can be partly explained by the use of the aerosol size distribution model for the phase function calculation. Straylight contamination can add to the bias, mainly at $1028 \mathrm{~nm}$. Lowering the normalization height to avoid the straylight can lead to normalization at levels that might contain some aerosol, albeit very small values. SCIAMACHY tangent height registration uncertainties can also add to the retrieval uncertainty. The effect of line-of-sight inhomogeneity, mainly at the UT/LS, is more complex and difficult to account for. Some of the observed differences were caused by instrument differences and atmospheric variability or mismatches, which requires further work to address adequately.

Generally, aerosol extinction measurements comparison is difficult in the stratosphere during a period of historically low background aerosol loading, more so in the UT/LS because of the highly variable atmospheric conditions in that region. Thomason and Peter (2006) carried out a comparison of various instruments that measure stratospheric aerosol extinction, and found that the agreement between these instruments is within 20-60\%. The accuracy and precision of the retrieved SCIAMACHY aerosol extinction profiles is well within these limits and demonstrate the capabilities of the SCIAMACHY limb measurements, as well as the OMPS LP algorithm to deliver good stratospheric aerosol extinction profiles. These aerosol products are suitable for scientific studies of various atmospheric events such as volcanic eruptions or high altitude clouds generated by biomass burning. Further tuning of the retrieval algorithm and the aerosol size distribution model, and a more extensive validation analysis using more instruments and a larger statistical sample would be beneficial for the retrieval by further understanding and quantifying the retrieval uncertainties. The SCIAMACHY and future OMPS aerosol extinction measurements would extend the existing stratospheric aerosol records in a significant way.

\subsection{Ozone concentration retrieval}

Figure 14 is a summary plot of the SCIAMACHY retrieved ozone concentration profile relative differences (percent) with SAGE II. The left panel shows the relative difference for Visible (red), Ultraviolet (blue), and University of Bremen (IUP) retrievals (yellow) for all events used in this study. The IUP ozone profile used here is Stratozone 2.0, which is based on simultaneous retrieval in the UV (Hartley-Huggins) and visible Chappuis bands (Sonkaew et al., 2009). The IUP retrieval corrects for aerosol extinction using constant aerosol climatology. The right panel shows the standard deviation (line) and the retrieval error or RSD (dash). The left panel shows that the retrieved ozone concentration profile (vis.) agrees well with the one from SAGE II, with $\sim 3 \%$ improvement over the IUP retrieval, which could be attributed to an improved aerosol extinction profile solution. IUP retrieval uses constant aerosol extinction climatology to correct for
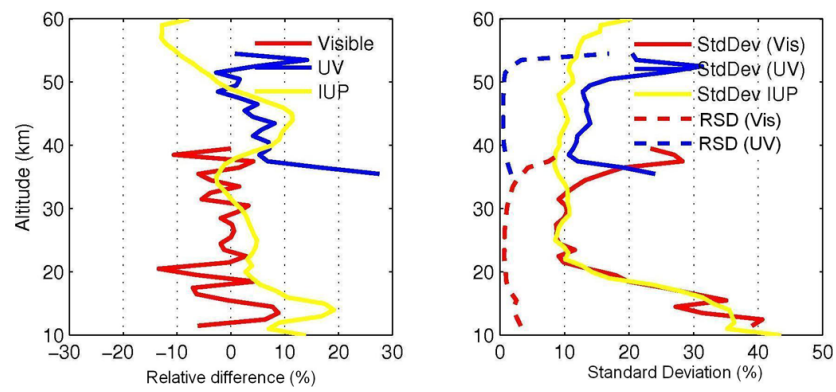

Fig. 14. Summary plot of the relative difference (percent) for all retrieved ozone profiles used in this study with SAGE II (left panel). The right panel shows the standard deviations, and the RSD.

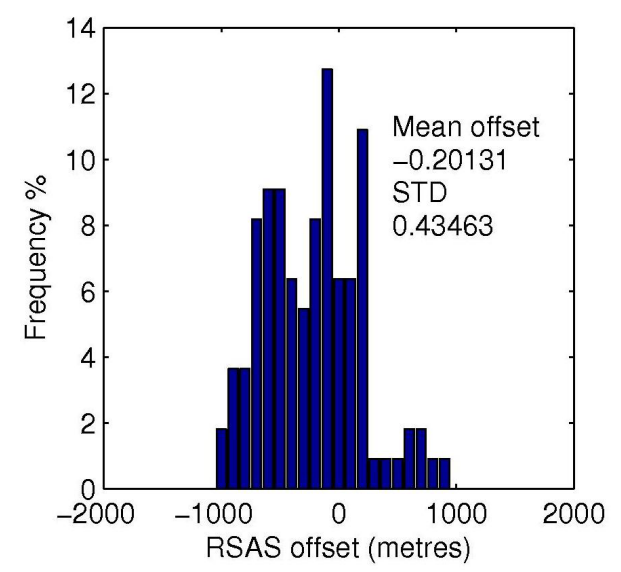

Fig. 15. Histogram of all detected tangent height offsets.

the stratospheric aerosol contribution, which can introduce a systematic bias in the ozone profile depending on the time and location of the measured profile. The standard deviation for both visible and IUP retrievals is $\sim 10 \%$. The RSD is very small compared to the standard deviation, mainly because SCIAMACHY reported errors were small. The natural atmospheric variability can also explain some of the observed differences between the standard deviation and the retrieval error.

\subsection{Tangent height registration}

Figure 15 shows a tangent height registration histogram of all detected altitude offsets. The mean offset detected is -200 $\mathrm{m}$, with a standard deviation of $430 \mathrm{~m}$. The observed standard deviation is comparable to the assumed tangent height accuracy of SCIAMACHY level 1 radiances of $300-400 \mathrm{~nm}$. A tangent height offset of $-140 \mathrm{~m}$ and standard deviation of $200 \mathrm{~m}$ for SCIAMACHY measurements in the tropical region was noted by von Savigny et al. (2009), which are based on pointing retrievals using TRUE (Tangent height Retrieval by UV-B Exploitation) (Kaiser et al., 2004). 


\section{Summary and conclusions}

The OMPS/LP retrieval algorithm is currently being tested with a large set of synthetic and proxy radiance data in order to gauge its performance and identify sources of bias and systematic errors. The results of this performance analysis are being used to fine-tune the algorithm. Using the synthetic radiances, we showed that the aerosol extinction coefficient can be retrieved from limb scatter measurements within $5 \%$ and a standard deviation better than $15 \%$ for the altitude range of $15-30 \mathrm{~km}$, which is more than sufficient to improve the OMPS/LP ozone products to be used as Environmental Data Records. Using SCIAMACHY limb measurements as a proxy, the study presented in this paper has allowed a direct comparison of the OMPS/LP algorithm products with SAGE II retrievals, under a wide range of atmospheric conditions, geo-locations, scattering solar angles and seasons. Such comparison is obviously difficult since it does involve instrument artifacts and effects (which are different for each sensor) and atmospheric variability. The retrieved aerosol extinction profiles agree with collocated SAGE II measurements on average to within $25 \%$, with a standard deviation of $35 \%$. A secondary outcome of this study shows that it is indeed possible to retrieve aerosol extinction profiles from SCIAMACHY LS data, which in turn, could lead to an improvement of the SCIAMACHY gaseous products in the UT/LS region.

Acknowledgements. The authors wish to acknowledge valuable discussions and comments with B. Wenny, K.-U. Eichmann, T. Sonkaew, and J. Burrows. We would also like to acknowledge valuable remarks given by two anonymous reviewers. Thanks to ESA for providing SCIAMACHY level 1 data used in this study, Institute of Environmental Physics (IUP), University of Bremen for providing the IUP ozone profiles, and for the SAGE II team at NASA LaRC for processing SAGE II version 6.2 measurements. The initial work took place during a visit by $G$. Taha at the University of Bremen. One of the Authors, G. Taha, is supported by NASA grant NNL07AA00C.

Edited by: E. Kyrölä

\section{References}

Borchi, F., Pommereau, J.-P., Garnier, A., and Pinharanda, M.: Evaluation of SHADOZ sondes, HALOE and SAGE II ozone profiles at the tropics from SAOZ UV-Vis remote measurements onboard long duration balloons, Atmos. Chem. Phys., 5, 13811397, doi:10.5194/acp-5-1381-2005, 2005.

Bourassa, A. E., Degenstein, D. A., Gattinger, R. L., and Llewellyn, E. J.: Stratospheric aerosol retrieval with optical spectrograph and infrared imaging system limb scatter measurements, J. Geophys. Res., 112, D10217, doi:10.1029/2006JD008079, 2007.

Bourassa, A. E., Elash, B., Degenstein, D., and Llewellyn, E. J.: Evolution of the stratospheric aerosol enhancement following the Kasatochi eruption: Odin-OSIRIS measurements, 5th Atmospheric Limb Conference, Finland, available online at: http://fmilimb.fmi.fi/5thlimbmeeting/presentations/Bourassa. pdf, 2009.

Bovensmann, H., Burrows, J. P., Buchwitz, M., Frerick, J., Noel, S., Rozanov, V. V., Chance, K. V., and Goede, A. P. H.: SCIAMACHY: Mission objectives and measurement modes, J. Atmos. Sci., 56(2), 127-150, 1999.

Flittner, D. E., Bhartia, P. K., and Herman, B. M.: O3 profiles retrieved from limb scatter measurements: Theory, Geophys. Res. Lett., 27, 2601-2604, 2000.

Gottwald, M., Bovensmann, H., Lichtenberg, G., Noël, S., von Bargen, A., Slijkhuis, S., Piters, A., Hoogeveen, R., von Savigny, C., Buchwitz, M., Kokhanovsky, A., Richter, A., Rozanov, A., Holzer-Popp, T., Bramstedt, K., Lambert, J.-C., Skupin, J., Wittrock, F., Schrijver, H., and Burrows, J. P.: SCIAMACHY, Monitoring the Changing Earth's Atmosphere, Published by DLR, 2006.

Herman, B. M., Ben-David, A., and Thome, K. J.: Numerical technique for solving the radiative transfer equation for a spherical shell atmosphere, Appl. Optics, 33, 1760-1770, 1994.

Herman, B. M., Caudill, T. R., Flittner, D. E., Thome, K. J., and Ben-David, A.: Comparison of the Gauss-Seidel spherical polarized radiative transfer code with other radiative transfer codes, Appl. Optics, 34, 4563-4572, 1995.

Hofmann, D. J. and Deshler, T.: Stratospheric cloud observations during formation of the Antarctic ozone hole in 1989, J. Geophys. Res., 96, 2897-2912, 1991.

Janz, S. J., Hilsenrath, E., Flittner, D., and Heath, D.: Rayleigh scattering attitude sensor, Proc. SPIE Int. Soc. Opt. Eng., 2831, 146-153, 1996.

Kaiser, J., von Savigny, C., Eichmann, K.-U., Noël, S., Bovensmann, H., Frerick, J., and Burrows, J. P.: Satellite Pointing Retrieval from Solar UV-B Radiation Scattered in the Atmosphere by the Earth's limb, Can. J. Phys., 82, 1041-1052, 2004.

Kalnay, E., Kanamitsu, M., Kistler, R., Collins, W., Deaven, D., Gandin, L., Iredell, M., Saha, S., White, G., Woollen, J., Zhu, Y., Chelliah, M., Ebisuzaki, W., Higgins, W., Janowiak, J., Mo, K. C., Ropelewski, C., Wang, J., Leetmaa, A., Reynolds, R., Jenne, R., and Joseph, D.: The NCEP/NCAR 40-year reanalysis project, B. Am. Meteorol. Soc., 77, 437-471, 1996.

Llewellyn, E. J., Lloyd, N. D., Degenstein, D. A., Gattinger, R. L., Petelina, S. V., Bourassa, A. E., Wiensz, J. T., Ivanov, E. V., McDade, I. C., Solheim, B. H., McConnell, J. C., Haley, C. S., von Savigny, C., Sioris, C. E., McLinden, C. A., Griffioen, E., Kaminski, J., Evans, W. F., Puckrin, E., Strong, K., Wehrle, V., Hum, R. H., Kendall, D. J.W., Matsushita, J., Murtagh, D. P., Brohede, S., Stegman, J., Witt, G., Barnes, G., Payne, W. F., Piché , L., Smith, K., Warshaw, G., Deslauniers, D. L., Marchand, P., Richardson, E. H., King, R. A., Wevers, I., McCreath, W., Kyrölä, E., Oikarinen, L., Leppelmeier, G. W., Auvinen, H., Mégie, G., Hauchecorne, A., Lefévre, F., de La Nöe, J., Ricaud, P., Frisk, U., Sjoberg, F., von Schéele, F., and Nordh, L.: The OSIRIS instrument on the Odin spacecraft, Can. J. Phys., 82, 411-422, 2004.

Loughman, R. P., Flittner, D. E., Herman, B. M., Bhartia, P. K., Hilsenrath, E., and McPeters, R. D.: Description and sensitivity analysis of a limb scattering ozone retrieval algorithm, J. Geophys. Res., 110, D19301, doi:10.1029/2004JD005429, 2005.

McLinden, C. A., Olsen, S., Hannegan, B., Wild, O., Prather, M. J., and Sundet, J.: Stratospheric ozone in 3-D models: A sim- 
ple chemistry and the cross-tropopause flux, J. Geophys. Res., 105(D11), 14653-14665, 2000.

Poole, L. R. and McCormick, M. P.: Airborne lidar observations of Arctic polar stratospheric cloud: Indications of two distinct growth stages, Geophys. Res. Lett., 15, 21-23, 1988.

Rault, D. F.: Ozone profile retrieval from Stratospheric Aerosol and Gas Experiment (SAGE III) limb scatter measurements, J. Geophys. Res., 110, D09309, doi:10.1029/2004JD004970, 2005.

Rault, D. F. and Loughman, R.: Stratospheric and upper tropospheric aerosol retrieval from limb scatter signals, Proceedings of the SPIE, 6745, 674509, doi:10.1117/12.737325, 2007.

Rault, D. F. and Taha, G.: Validation of ozone profiles retrieved from SAGE III limb scatter measurements, J. Geophys. Res., 112, D13309, doi:10.1029/2006JD007679, 2007.

Rodgers, C. D.: Inverse methods for atmosphere sounding: Theory and practice, World Scientific Publishing Co, Singapore, 238 pp., 2000.

Sonkaew, T., Rozanov, V. V., von Savigny, C., Rozanov, A., Bovensmann, H., and Burrows, J. P.: Cloud sensitivity studies for stratospheric and lower mesospheric ozone profile retrievals from measurements of limb-scattered solar radiation, Atmos. Meas. Tech., 2, 653-678, doi:10.5194/amt-2-653-2009, 2009.

Thomason, L. W.: A diagnostic stratospheric aerosol size distribution inferred from SAGE II measurements, J. Geophys. Res., 96, 22501-22508, 1991.

Thomason, L. W. and Peter, T.: Assessment of Stratospheric Aerosol Properties (ASAP), SPARC Report No. 4, WCRP-124, WMO/TD-No. 1295, available online at: http://www.atmosp. physics.ca/SPARC/, 2006.

Thomason, L. W. and Taha, G.: SAGE III Aerosol Extinction Measurements: Initial Results, Geophys. Res. Lett., 30(12), 1631, doi:10.1029/2003GL017317, 2003.
Vanhellemont, F., Fussen, D., Mateshvili, N., Tétard, C., Bingen, C., Dekemper, E., Loodts, N., Kyrölä, E., Sofieva, V., Tamminen, J., Hauchecorne, A., Bertaux, J.-L., Dalaudier, F., Blanot, L., Fanton d'Andon, O., Barrot, G., Guirlet, M., Fehr, T., and Saavedra, L.: Optical extinction by upper tropospheric/stratospheric aerosols and clouds: GOMOS observations for the period 20022008, Atmos. Chem. Phys., 10, 7997-8009, doi:10.5194/acp-107997-2010, 2010

von Savigny, C., Kaiser, J. W., Bovensmann, H., Burrows, J. P., McDermid, I. S., and Leblanc, T.: Spatial and temporal characterization of SCIAMACHY limb pointing errors during the first three years of the mission, Atmos. Chem. Phys., 5, 2593-2602, doi:10.5194/acp-5-2593-2005, 2005.

von Savigny, C., Sonkaew, T., Dikty, S., Eichmann, K.-U., Rozanov, A., Weber, M., Bovensmann, H., and Burrows, J. P.: New stratospheric ozone results from SCIAMACHY/Envisat, 5th Atmospheric Limb Conference, Finland, available online at: http:// fmilimb.fmi.fi/5thlimbmeeting/presentations/Savigny.pdf, 2009.

Wang, H. J., Cunnold, D. M., Thomason, L. W., Zawodny, J. M., and Bodeker, G. E.: Assessment of SAGE version 6.1 ozone data quality, J. Geophys. Res., 107(D23), 4691, doi:10.1029/2002JD002418, 2002.

Wang, P. H., Kent, G. S., McCormick, M. P., Thomason, L. W., and Yue: G. K.: Retrieval analysis of aerosol size distribution with simulated extinction measurements at SAGE III wavelengths, Appl. Optics, 35, 433-440, 1996.

Yue G. K. and Deepak, A.: Retrieval of stratospheric aerosol size distribution from atmospheric extinction of solar radiation at two wavelengths, Appl. Opt., 22, 1639-1645, 1983. 